Article

\title{
Future of Sustainable Management of Energy Companies in Terms of Attitudes and Preferences of the Younger Generation
}

\author{
Arnold Pabian ${ }^{1, * \mathbb{D}}$, Katarzyna Bilińska-Reformat ${ }^{2}$ and Barbara Pabian ${ }^{2}$ \\ 1 Department of Management, Czestochowa University of Technology, 42-201 Częstochowa, Poland \\ 2 Department of Marketing Management and Tourism, University of Economics in Katowice, 40-287 Katowice, \\ Poland; katarzyna.bilinska-reformat@ue.katowice.pl (K.B.-R.); barbara.pabian@ue.katowice.pl (B.P.) \\ * Correspondence: arnold.p@wp.pl
}

Citation: Pabian, A.;

Bilińska-Reformat, K.; Pabian, B.

Future of Sustainable Management of

Energy Companies in Terms of

Attitudes and Preferences of the

Younger Generation. Energies 2021, 14,

3207. https://doi.org/10.3390/

en14113207

Academic Editor: Ben McLellan

Received: 31 March 2021

Accepted: 28 May 2021

Published: 31 May 2021

Publisher's Note: MDPI stays neutral with regard to jurisdictional claims in published maps and institutional affiliations.

\begin{abstract}
The future of the energy sector depends on the younger generation. The paper presents the results of the study, the aim of which was to determine to what extent younger generation is proecological and pro-social, and whether they will include pro-ecological and pro-social activities in the management of energy companies. It is especially important to implement sustainable management in the energy sector. The study found that only $33.9 \%$ of young people are highly pro-ecological and $28.6 \%$ highly pro-social. As many as $83.0 \%$ of the younger generation show low and medium interest in environmental protection. Declarations of young people concerning high degree of inclusion of pro-ecological and pro-social activities in management are at the level of $49.9 \%$ and $58.1 \%$. However, in many cases, these intentions do not coincide with the high pro-ecological and pro-social attitude of young people. This means that their future activity for sustainable management may be low. According to the survey, the younger generation to a large extent is not prepared to continue efforts for sustainable development in the future in the energy companies.
\end{abstract}

Keywords: sustainable development; sustainable management; energy companies; younger generation; future of management

\section{Introduction}

Energy companies, like companies from other sectors of the economy, significantly contribute to the deterioration of the condition of our planet. As a result of the growing ecological and social threats, the Earth is losing its potential, heading towards the limits of nature's tolerance. In the past 50 years, the impact of human enterprise and human numbers on the earth has been devastating. We are living at a time of peak consumption and peak waste [1] As D. Fogel emphasizes, modern industrial society may collapse if resources are not responsibly managed and are abused [2]. There is no business to be done on a dead planet [3]. Research shows that humanity now needs a regenerative capacity of 1.6 Earth to guarantee a supply of goods and services that are consumed globally each year [4].

The deteriorating condition of our planet makes the consideration of environmental issues central to the development of energy policy and the activities of the energy industry. It is necessary to look for more sustainable forms of energy and improve environmental performance by industrial operators [5]. Energy, economics, and the environment are interdependent [6]. Climate change and security of energy supply are the main sustainability issues today [7].

In order to reduce ecological and social risks, people have been implementing the concept of sustainable development for over a quarter of a century. However, the results of numerous initiatives taken on a global and local scale are still insufficient. Adding the word "sustainable" to our vocabulary, to our reports, programs, and papers, to the names of our academic institutes and research programs, and to our community initiative, is not sufficient to ensure that our society becomes sustainable [8]. This problem also 
applies to the energy sector. Although the energy sector is actively involved in sustainable development, which can be seen in the gradual departure from fossil fuels, including coal, and the use of renewable energy sources, there are still many untapped opportunities to improve this sector in terms of sustainability.

Sustainable management is a new and important challenge for energy companies. Sustainable management is a progressive concept that aims to accelerate sustainable development. The following statement by $\mathrm{S}$. Cohen still remains valid: sustainability management is in its infancy; it today will not be able to predict its pace, shape, or trajectory. Sustainability management is the practice of economic production and consumption that minimizes environmental impact and maximizes resource conservation and reuse. At the heart of sustainability management is a concern for the future [9].

Introducing sustainable management to energy companies is not only a matter of the present, but also of the future. Already started, or planned, transformation of energy companies into sustainable energy companies should be continued in the future by the next generation. This generation currently includes young people who will soon take over the power in energy companies. In order for these enterprises not to leave the path of sustainable development in the future, but to strengthen their position on it, their managers must be pro-ecological and pro-social, and show the will to implement pro-ecological and pro-social activities in their companies. The study, conducted by the authors of this article on a sample of 773 young people, explains these issues. The purpose of the study was to determine to what extent young people are pro-ecological and pro-social, and whether they will include activities aimed at environmental protection and solving social problems in the management of these companies, if they occupy the highest positions in energy companies. It is very important to clarify these issues. Humanity must not slow down sustainable development because the condition of our planet is deteriorating at an accelerated pace. Researchers estimate that the world is changing exponentially, and, in the next 10 years, more may happen than for the 100 years that have passed before that [10]. This also applies to the growing environmental and social problems in the energy sector. Therefore, slowing down or failing to act for sustainable development in the future with the present high rate of energy production and consumption, means exceeding nature's tolerance limits and further irreversible deterioration of the condition of the Earth.

The authors of the paper use the terms of "sustainable development" and "sustainability" interchangeably. They share the view of E. Holden et al., according to which "sustainable development" and "sustainability" entail the same ideas; therefore, using them interchangeably is fully justified [11].

\section{Literature Review}

The research problems discussed in this paper are not reflected in the scientific literature. To support this thesis, the literature review in the aspect of the issue discussed in the paper is presented below.

Energy companies significantly contribute to the increase in environmental and social threats. Scientific literature devotes a lot of space to ecological and social threats and their negative impact on the condition of the Earth. E. Holden et al. lists the following types of planetary boundaries: climate change, loss of biosphere integrity, nitrogen and phosphorus flows to the biosphere and oceans, land-system change, atmospheric aerosol loading, stratospheric ozone depletion, ocean acidification, global freshwater use, and the global hydrological cycle, chemical pollution, and the release of novel entities [11]. S. Jeanrenaud and J.-P. Jeanrenaud associate ecological and social risks with sustainable development challenges, indicating: 1 . key environmental challenges: climate, water, biodiversity, resource depletion, waste; and 2. key social challenges: population dynamics, poverty and inequality, exploitation, and well-being [3]. As M. Lenox and A. Chatterji claim, the Earth is in trouble because of its ecological and social dangers. The existential threat posed by a changing and environmental "unsustainability" is leading to dire predictions about the future of its land, its sea, and its people. The threat will likely unfold slowly, but 
once it grains momentum, it might be impossible to stop. The impact could be enormous, as significant as war or plague; in fact, wars and plagues may be direct outcomes of climate change and environmental degradation [12]. No less pessimistic opinions are expressed by J. A. Carbo et al.: from an ecological standpoint, the current business methods of marketing, extraction, production, and disposal push us away from a sustainable planet and towards a catastrophic level of destruction. Business practices are currently leading to an environment that is not conducive to human life in the long run and ecological problems that are leading to sicknesses and deaths in the short run [13].

Growing ecological and social threats have led to the development of the concept of sustainability. The term sustainability represents the ability of the whole or part of the biotic environment to extend its form in the future [14]. It is the ability of a system to maintain or renew itself perpetually [15]. The notion of sustainability is not used consistently and has different meanings for different people and organizations. G. Haugan presents various definitions of this concept (Basic Definition, Forestry Definition, Systems Definition, MIT Sloan School of Management Definition, Environmental Sustainability, Ecological Footprint, Generational Sustainability, Sustainability as a Process Destination) [8]. A similar opinion is expressed by E. Holden et al.: sustainable development is called many things, including "a process of human activity", "a social movement", "a practice", "a discourse", and "a narrative". Sustainable development is primarily a process of change [11]. M. Ottosson and A. Parment, refer to a soft and hard interpretation of the term sustainability. A soft interpretation of the term-“"weak sustainability" — entails us having to allow certain resources to be substituted for others. Hard interpretation of the term-“"strong sustainability" - rejects the line of reasoning that allows different parts of the sustainability term to be substituted or balanced against one another [16]. Sustainable development is an integrated approach for the socioeconomic modernization and advancement of a society by both efficient utilization and minimal depletion of natural resources. It is a development that causes minimum negative externalities to the environment [17]. Sustainability is becoming a key business imperative. For the sake of their long-term success, companies have increasingly recognized the need to ensure the future of both humans and the Earth [18]. Issues of ethics, social responsibility, and sustainability in business have moved from marginal to mainstream [19]. According to G. Varghese and L. Viswanathan, the key to a sustainable future is the: awareness of the ecological limits, use of human ingenuity to design ways to live within the bounds, adoption of practices that reduce human imprint and keeping "going green" central to decision [20]. As L. P. Thiele claims, to live sustainably is to take responsibility for our lives and our communities [1].

Scientific literature considers various problems concerning energy in the field of sustainability. Here are some examples. M. Andrés et al. reviewed the literature in order to identify and categorize the drivers that motivate energy companies to adopt Corporate Social Responsibility (CSR). They divided the motivating factors for responsibility in the energy sector into three groups: internal drivers, connecting drivers, and external drivers [21]. T. E. Thorhallsdottir dealt with the problem of evaluating and ranking energy projects by environmental impact in Iceland. The final output was a one-dimensional ranking obtained by analytical hierarchical process considering total predicted impacts, total site values, risks, and uncertainties, as well as special site values [22]. X. Pang et al. attempted to find possibilities for comprehensive sustainability assessment among published energy environment models and the linking of renewable energy analysis to landscape and biodiversity issues through land use concerns) [7]. S. Zheng and co-authors conducted a regression analyses on data collected in 29 provinces in China as the first case study to investigate the moderating effect of energy service companies in relationships between urbanization, industrialization, and $\mathrm{CO}_{2}$ emissions [23]. X. Yan et al. studied the impact of risk-taking level on green technology innovation. They considered energyintensive listed companies operating in China from 2011 to 2017 [24].

Despite undertaking numerous research initiatives and implementing their effects into practice, the activity of enterprises, including energy enterprises, in the sphere of 
sustainable development is still insufficient. Research shows that corporate involvement in the sustainable development goals is still limited. The involvement is largely symbolic and intentional, rather than substantive [25]. Sustainable management is a modern concept that can accelerate sustainable development also in the energy sector. Sustainable management is the process of achieving goals by enterprises considering the principles of sustainable development [26]. Sustainable management is also defined as the development of new initiatives in an organization to sustain, improve, and renew the environmental, social and societal quality of its business processes and the products and services these business processes produce [27]. Research clearly shows that effective implementation of the sustainability strategy occurs when top management is involved in it [28]. New strategies that are related to environmental and social challenges often require new qualifications. $R$. Eccles and G. Serafeim recognize the shortage of competences as one of the main barriers to the development of the strategy of sustainability [29]. Sustainable organizations require sustainable leadership [13]. The main functions of sustainable management are briefly characterized below.

Sustainable management begins with the formulation of the mission, strategic goals, tactical goals, operational goals, and strategic plans, tactical plans, and operational plans of the company. A goal is a desired future circumstance or condition that the organization attempts to realize [30]. Managers use planning to identify and select goals, as well as directions of an organization's activities [31]. From the point of view of sustainable management, it is necessary to include activities for sustainable development in the mission, goals and plans of companies. As a result, it becomes an integral and permanent part of their functioning. Risk management is an important element of planning activity, because even the best prepared plan does not guarantee the achievement of all goals. As R. Templar advises, you must have a plan B and a plan C. You have to plan for disasters [32].

Sustainable management also requires considering sustainable development activities in various organizational processes. Companies should integrate social, environmental and economic concerns into all areas of the organizations [28]. In the organizational structures of enterprises, it is recommended to create independent positions or departments for sustainability. Organizing and performing work in positions that create an organizational structure should be pro-ecological and pro-social. In this case, it is about the use of economical and safe devices, the use of ecological materials, compliance with health and safety regulations, and compliance with labor law. In addition, it is recommended that the management of enterprises create special pro-social programs that are not imposed by applicable law, such as: "Zero accidents" or "Work-life balance". It is also important to create a friendly "green" work environment for employees. Research shows that a friendly, "green" workplace makes as many as 2/3 of the respondents feel healthier [33].

Motivating is an important function of sustainable management. Understanding motivation is the key to the successful management of people [34]. High motivation allows for using $80-90 \%$ of the employees' potential [35]. In order to encourage employees to involve in pro-ecological and pro-social activity, various means of motivating for specific achievements in this area can be used, including cash rewards (additional remuneration and bonuses), material prizes, diplomas of recognition, medals, and statuettes. The working atmosphere created by the manager is a motivating factor in activities for sustainable development. Its positive manifestations include expressing recognition for pro-ecological and pro-social achievements, ethical behavior, friendly treatment of team members, listening to their opinions and suggestions, fair evaluation, and assistance in solving problems. Co-workers can also motivate the employee to pro-ecological and pro-social activities. If employees see that their colleagues take sustainability seriously and willingly engage in solving environmental and social problems in their workplace, they will do likewise. This is because they want to belong to the group, be accepted by it and not risk being excluded.

Control is also included in the area of sustainable management. Controlling involves evaluating results in relations to plans or objectives and deciding what action to take next [36]. In a more specific approach, control consists in comparing actual performance of 
tasks with what has been planned. The key areas of control in the field of sustainability include: 1. control of the course of activities in the field of sustainability, 2. control of the use of resources in terms of sustainability, and 3. control of cash expenditure on activities in the field of sustainability.

Researchers understand that sustainable management requires sustainable leadership [13]. To save the Earth, we will need expert managers to recognize great ideas, turn them into products and figure out how to sell them to the mass market [12]. However, there are no detailed studies explaining what features sustainable managers should have. This gap is to some extent filled by A. Pabian, A. Brzozowska and B. Pabian. In their opinion, the basic condition for a genuine and effective involvement of a manager in sustainability issues is his or her knowledge in this area and socio-ecological sensitivity. They include socio-ecological sensitivity and knowledge in the area of sustainability among the most important features of sustainable managers. Social and environmental sensitivity makes that managers feel responsible for the state of the planet on which they live. They want to work for future generations so that they can both survive and burgeon. They do not only focus on the present and the near future, but also seek to anticipate the social and environmental consequences of their decisions in the long run. Sustainable managers understand and accept sustainable development. They have extensive knowledge of environmental and social risks present on a local and global scale and ways to reduce them. They also know whether and what environmental and social problems may result from their activity and how to eliminate them [37]. These features are universal in nature and apply to all companies, including energy companies.

As can be seen from the literature review presented above, the term sustainable management is not used in relation to energy companies. It is a new type of management that should be applied in this sector of the economy. Sustainable management can greatly accelerate sustainable development. In this case, it is about sustainable management in functional approach, i.e., sustainable planning, sustainable organizing, sustainable leading, sustainable controlling [37]. No information has been found in the scientific literature on the future of sustainable management in the energy sector, nor the role performed in this area by the younger generation that will soon take over the power in energy companies. While there are scientific articles devoted to the younger generation, an example of which is the publication of K. Bilinska-Reformat and M. Stafańska [38], the issues discussed in this article are not reflected in them. Therefore, the research problems undertaken in this paper are fully justified.

\section{Research Method}

The purpose of the study is to determine to what extent the younger generation is pro-ecological and pro-social, and whether they will include pro-ecological and pro-social activities in the management of enterprises, including energy companies in the future (this management should be based on the concept of sustainable management). The problem is important because the future of sustainable energy development depends on the attitudes and preferences of the younger generation, which will soon be taking power in the companies that produce it.

Adopting the above-mentioned research goals is justified in the light of the Literature Review. As demonstrated in the Literature Review, the basic condition for a genuine and effective involvement of a manager in sustainability issues is his or her knowledge in this area and socio-ecological sensitivity. These basic conditions should be met by every candidate for a manager in order to properly develop sustainable management in energy companies. Thus, a young person who meets these conditions is generally better prepared to perform the function of a sustainable manager than other candidates. Our research shows the structure of attitudes and views of the younger generation analyzed in this aspect.

In order to achieve the determined research goals, a research tool in the form of a questionnaire was developed, the minimum sample size was defined and the method of 
communication with respondents was determined. After the research was conducted, its results were compiled and analyzed, and conclusions were formulated. Pro-ecological and pro-social attitudes, as well as preferences and future behaviors of the younger generation, were examined using a 9-point scale. Consequently, it was possible to assign respondents to low, medium, or high pro-ecological and pro-social orientation, and to formulate conclusions about their future behavior in enterprises.

The survey was conducted in Poland in February 2020 by contacting respondents aged 19-24 in person. Personal contact with the respondents was possible at that time because teaching in Poland took place in a traditional and not virtual way (this was the period preceding the introduction of restrictions related to the Covid-19 pandemic). The research tool was a survey questionnaire in paper form. It contained seven questions aimed to solve the research problem. Each question included a point scale on which the answers were marked. The study took into consideration the division of the study group in terms of gender (at the end of the questionnaire, there was a question regarding the respondents' gender). The research plan did not allow for the division of the respondents according to other criteria and presentation of the research results from their perspective.

Students of technical faculties (energy, construction, materials engineering) and students of management participated in the study. The choice of this group of people as a representative of the younger generation was justified because these people will soon start working and certainly many of them will occupy managerial positions in enterprises.

The focus on a wider group of respondents resulted from a simple reason: as our research and observations show, many graduates of the energy faculty do not work in this sector, and vice versa-graduates of other faculties find employment in the energy sector. The future jobs and careers of respondents in this part of Europe depend on the labor market situation after graduation, and, more specifically, on the number of vacancies offered in individual sectors of the economy. Certainly, many of the respondents will work in the energy sector. However, it is currently difficult to estimate this number. There is one more argument in favor of the study group. The essence of sustainable management is, among other things, minimizing the consumption of production factors. One such factor is energy. Sustainable management can contribute to the reduction of its consumption in various sectors of the economy, which directly affects the energy sector: lower energy demand results in reduced extraction of the minerals needed for its production. Thus, the younger generation developing sustainable management in other areas of the economy will also to some extent affect the sustainability of the energy sector.

The research focused on the preferences and future behavior of the younger generation regarding environmental protection and social problems. The division into ecological and social problems is fully justified because the essence of sustainable management is counteracting environmental and social threats. They are different types of threats, and, in many cases, there is no relationship between them. For example, environmental pollution (ecological problem) has no impact on crime, drug addiction, nor alcoholism (social problems).

The research was performed using the representative method. The survey process covered 773 people aged 19-24 (302 men and 471 women). The number of respondents meets the assumptions of the minimum sample size. The minimum sample size was determined in order to draw conclusions about the studied population. In determining the necessary sample size, the following steps were taken:

- $\quad$ the accuracy of the estimation was established, while assuming the specified maximum error of the estimate,

- a high level of confidence was assumed, and

- $\quad$ assumptions about the proportion of the studied population were made.

Assuming that the order of magnitude of the success probability $p$ is not known, the minimum number of units was 753 with the following assumptions: significance level $\alpha=0.01$, maximum error of the estimate $d=5 \%(u \alpha=2.7434)$. 
The study was conducted in Poland, which is located in Central and Eastern Europe and is a member of the European Union. The survey is largely representative of the countries of the region. These countries cooperate with each other in pursuit of energy integration. They have similar goals and plans in this regard. They also develop sustainable energy, adapting to the requirements of the European Union. They educate young people in the field of sustainable development and promote this development in their societies. Young citizens of Central and Eastern Europe come from countries with a similar level of economic development, and a similar cultural profile. They move freely between their countries belonging to the European Union (internal borders in the European Union have been abolished under the Schengen agreements), establish contacts, and exchange views. This favors the blurring of the differences between young people from this part of the world.

\section{Results}

The study was to discover to what extent young people are pro-ecological and prosocial, and whether they will include activities aimed at environmental protection and solving social problems in the management of the companies when occupying the top positions in companies, including the energy ones. The next part of the paper first presents the results of the study on the pro-ecological approaches of young people, and then their pro-social attitudes, linking these problems with their future activities in enterprises.

The authors of the paper were interested in the issues related to the pro-ecological attitudes of the younger generation and their future pro-ecological behavior in enterprises. The questions aimed to determine:

(a) whether young people are pro-ecological, and, therefore, they try to protect the natural environment of humans from destruction (they save water, segregate rubbish, use energy-saving devices, etc.),

(b) whether young people are interested in environmental issues, and, thus, if they follow news and programs on this issue broadcast by the Internet, TV, radio, press, and whether they develop their knowledge about ecological threats and the ways of counteracting them,

(c) whether they will limit the negative impact of their companies on the natural environment when occupying the top management positions in enterprises in the future, and

(d) what percentage of profit of their future companies they will be ready to spend on financing pro-ecological projects.

The problem of allocating some percentage of the profit to finance pro-ecological and pro-social projects in future workplaces of young people, discussed in point $\mathrm{d}$ and later in this article in point $c$, is quite complex. The amount of these funds depends on numerous external and internal conditions. By asking the respondents questions about the percentage of profit allocated for financing sustainability, the aim was to discover the intentions of the younger generation in this regard. These questions made it possible to discover, at least approximately, whether sustainability will be a priority for young people and whether they will allocate significant financial resources to these matters in their enterprises or whether they do not treat this area as a priority, which will be reflected in its much more modest financing. Table 1 and Figure 1 show the results of the research on the research problems a-d. 
Table 1. Pro-ecological orientation of the younger generation-the current state and preferences regarding future proecological activities in enterprises.

\begin{tabular}{|c|c|c|c|c|c|c|c|c|c|c|}
\hline \multirow{2}{*}{\begin{tabular}{|c|}
$\begin{array}{c}\text { Pro-Ecological } \\
\text { Orientation }\end{array}$ \\
Rating scale \\
\end{tabular}} & \multicolumn{4}{|c|}{ Low } & \multicolumn{3}{|c|}{ Medium } & \multicolumn{3}{|c|}{ High } \\
\hline & 0 & 1 & 2 & 3 & 4 & 5 & 6 & 7 & 8 & 9 \\
\hline \multirow{2}{*}{$\begin{array}{l}\text { Pro-ecological attitudes of } \\
\text { young people }\end{array}$} & 19 & 24 & 36 & 53 & 112 & 140 & 127 & 147 & 78 & 37 \\
\hline & \multicolumn{4}{|c|}{$132(17.1 \%)$} & \multicolumn{3}{|c|}{$379(49.0 \%)$} & \multicolumn{3}{|c|}{$262(33.9 \%)$} \\
\hline \multirow{2}{*}{ Interest in ecology } & 56 & 54 & 93 & 111 & 100 & 128 & 100 & 63 & 46 & 22 \\
\hline & \multicolumn{4}{|c|}{$314(40.6 \%)$} & \multicolumn{3}{|c|}{$328(42.4 \%)$} & \multicolumn{3}{|c|}{$131(17.0 \%)$} \\
\hline \multirow{2}{*}{$\begin{array}{l}\text { Future pro-ecological } \\
\text { activity in the enterprise }\end{array}$} & 7 & 6 & 19 & 35 & 69 & 104 & 147 & 158 & 122 & 106 \\
\hline & \multicolumn{4}{|c|}{$67(8.7 \%)$} & \multicolumn{3}{|c|}{$320(41.4 \%)$} & \multicolumn{3}{|c|}{$386(49.9 \%)$} \\
\hline
\end{tabular}

Source: own research.

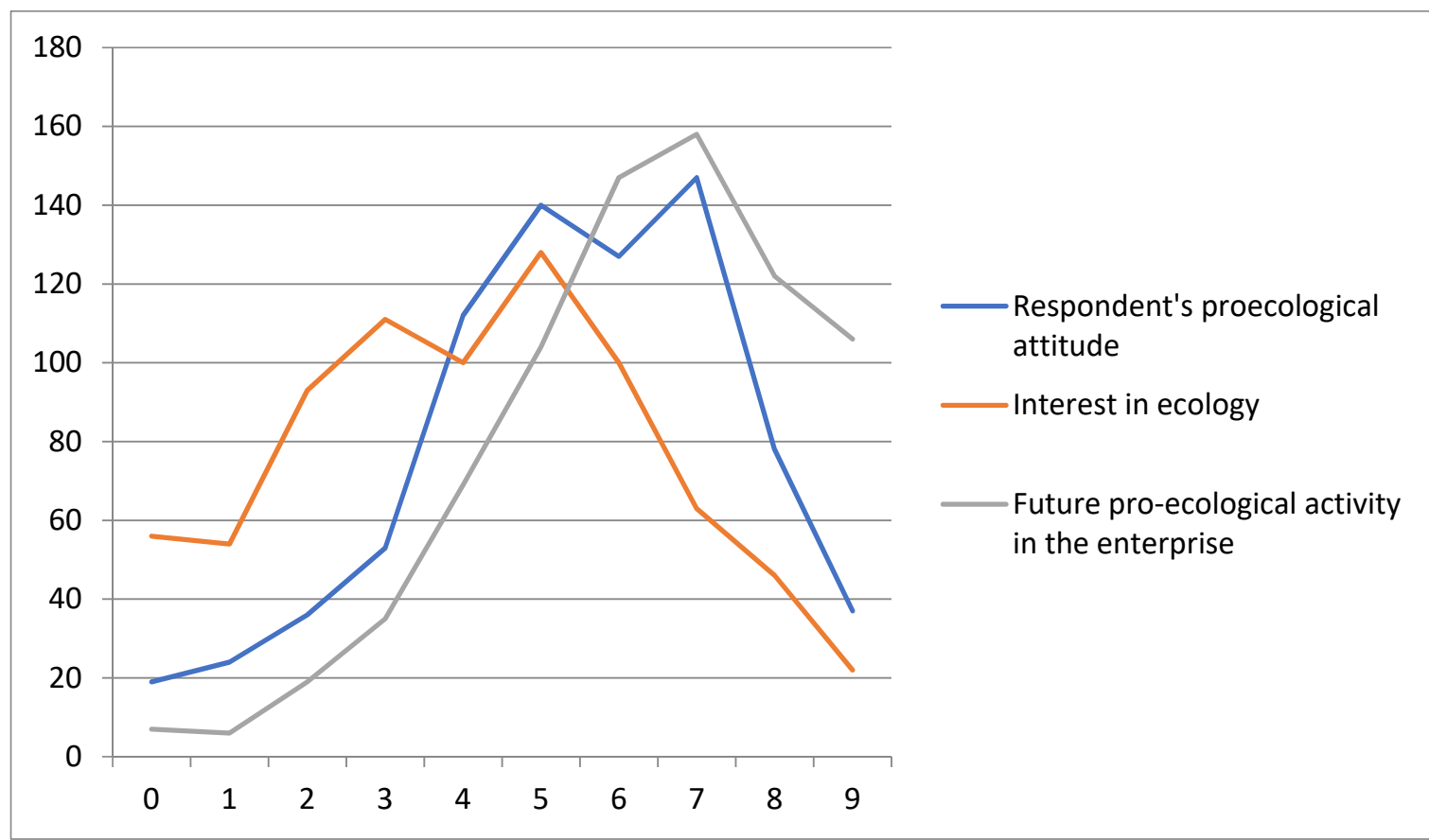

Figure 1. The structure of the pro-ecological orientation of the younger generation. Source: own study (based on Table 1).

As can be seen from the presented figures (Table 1 and Figure 1), only 33.9\% of young people are characterized by a high degree of pro-ecological attitudes. Moreover, as much as $83.0 \%$ of the younger generation shows low and medium interest in environmental protection. It should be emphasized that knowledge about environmental protection has a serious impact on the pro-ecological attitudes and people's behavior. It allows for better understanding of sustainable development and is a source of information on local and global environmental threats. It indicates professional methods and tools enabling their reduction or elimination. Lack of adequate knowledge in the field of environmental protection may constitute a serious obstacle for the younger generation in taking proecological activities in future workplaces that make a real contribution to sustainable development. The current pro-ecological attitudes of young people, not supported in most cases with reliable knowledge, are rather shallow and superficial. They have been shaped by the fashion for ecology and may change if this fad passes.

Only half of young people (49.9\%) declare a high level of pro-ecological activity of their enterprises, when occupying the highest managerial positions. This means that they will include pro-ecological activities in the management of enterprises to a large extent. 
Data on the part of the profit that young people would like to spend on financing pro-ecological projects in their enterprises is not optimistic. This problem is reflected in the figures in Table 2 and Figure 2. It results from these data that only $26.3 \%$ of respondents want to spend over $29 \%$ of their companies' profit on financing pro-ecological projects.

Table 2. Declarations on the financing of pro-ecological and pro-social projects in enterprises by the younger generation.

\begin{tabular}{|c|c|c|c|c|c|c|c|c|c|c|c|c|}
\hline $\begin{array}{l}\text { Orientation Concerning } \\
\text { Project Financing }\end{array}$ & \multicolumn{4}{|c|}{ Low } & \multicolumn{4}{|c|}{ Medium } & \multicolumn{4}{|c|}{ High } \\
\hline $\begin{array}{l}\text { company's profit } \\
\text { in percent }\end{array}$ & 0 & $1-9$ & $10-19$ & $20-29$ & $30-39$ & $40-49$ & $50-59$ & $60-69$ & $70-79$ & $80-89$ & $90-99$ & 100 \\
\hline \multirow{2}{*}{ Financing pro-ecological projects } & 17 & 214 & 229 & 110 & 85 & 48 & 32 & 18 & 4 & 9 & 2 & 5 \\
\hline & \multicolumn{4}{|c|}{$570(73.7 \%)$} & \multicolumn{4}{|c|}{$183(23.7 \%)$} & \multicolumn{4}{|c|}{$20(2.6 \%)$} \\
\hline \multirow{2}{*}{ Financing pro-social projects } & 25 & 232 & 192 & 106 & 85 & 55 & 35 & 21 & 9 & 6 & 1 & 6 \\
\hline & \multicolumn{4}{|c|}{555 (71.8\%) } & \multicolumn{4}{|c|}{$196(25.4 \%)$} & \multicolumn{4}{|c|}{$22(2.8 \%)$} \\
\hline
\end{tabular}

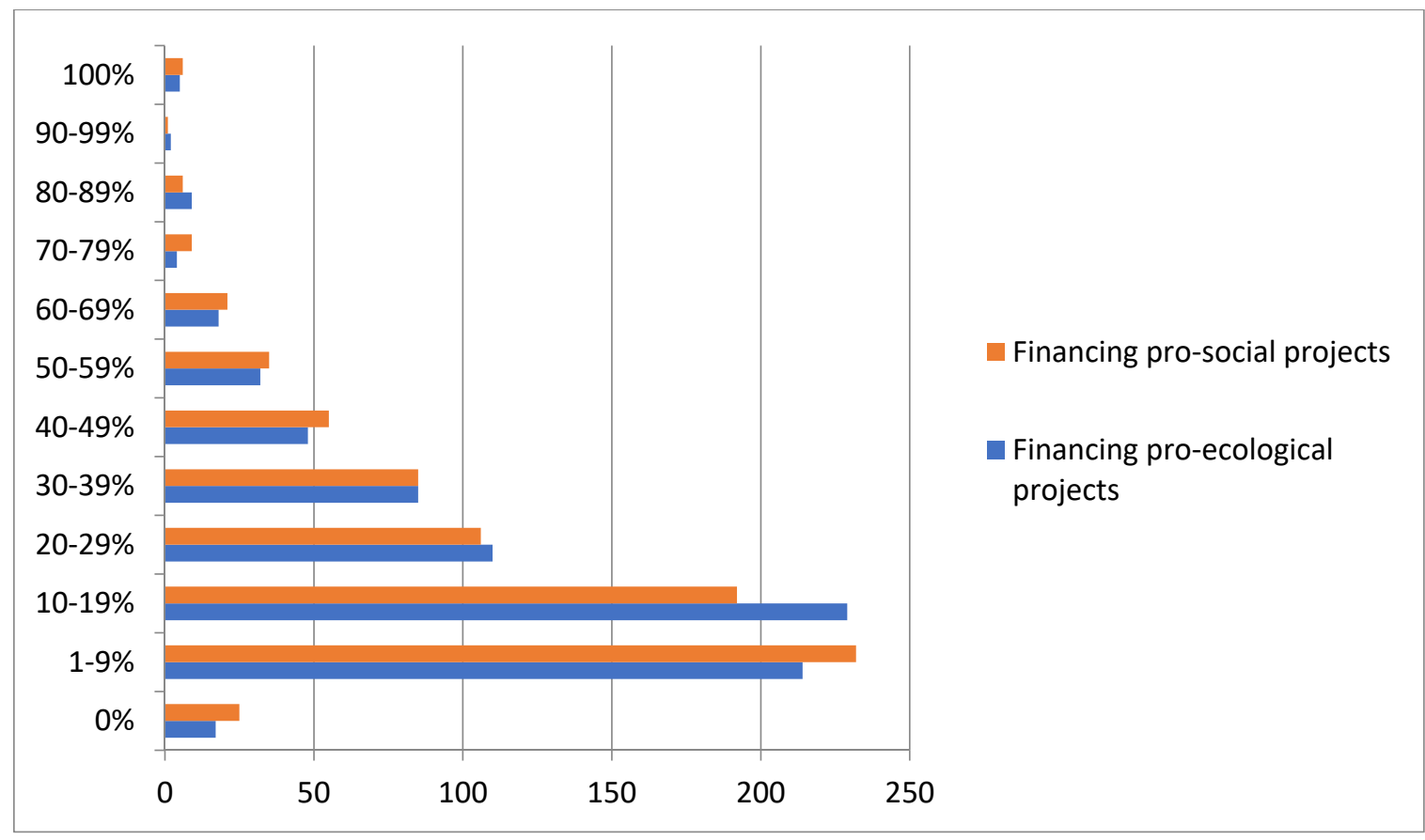

Figure 2. The percentage of the company's profit declared by the younger generation to be allocated to financing proecological and pro-social projects. Source: own study (based on Table 2).

Apart from being pro-ecological, pro-social attitude is the second fundamental pillar of sustainability. The authors of the paper were interested in the following issues regarding the pro-sociality of young people and their future pro-ecological behavior in enterprises, including energy companies:

(a) are young people pro-social, i.e., do they try to help the poor, disabled, sick, addicted to alcohol, drugs, victims of natural disasters, etc., supporting them materially or financially, including through charity foundations, taking part in charity events, volunteering, or otherwise?

(b) will they engage their companies in pro-social activities when occupying top management positions in enterprises?

(c) what percentage of profit are they ready to allocate in their companies to finance pro-social projects? 
Table 3 and Figure 3 show the results of the study on the above problems.

Table 3. Pro-social orientation of the younger generation-the current state and preferences regarding future pro-social activities in enterprises.

\begin{tabular}{|c|c|c|c|c|c|c|c|c|c|c|}
\hline \multirow{2}{*}{$\begin{array}{l}\text { Pro-Social Orientation } \\
\text { Rating scale }\end{array}$} & \multicolumn{4}{|c|}{ Low } & \multicolumn{3}{|c|}{ Medium } & \multicolumn{3}{|c|}{ High } \\
\hline & 0 & 1 & 2 & 3 & 4 & 5 & 6 & 7 & 8 & 9 \\
\hline \multirow{2}{*}{$\begin{array}{l}\text { Pro-social attitudes of } \\
\text { young people }\end{array}$} & 35 & 37 & 54 & 88 & 89 & 112 & 137 & 118 & 60 & 43 \\
\hline & \multicolumn{4}{|c|}{$214(27.7 \%)$} & \multicolumn{3}{|c|}{338 (43.7\%) } & \multicolumn{3}{|c|}{$221(28.6 \%)$} \\
\hline \multirow{2}{*}{$\begin{array}{l}\text { Future pro-social activity in } \\
\text { the enterprise }\end{array}$} & 7 & 5 & 10 & 34 & 62 & 86 & 120 & 144 & 131 & 174 \\
\hline & \multicolumn{4}{|c|}{$56(7.2 \%)$} & \multicolumn{3}{|c|}{$268(34.7 \%)$} & \multicolumn{3}{|c|}{449 (58.1\%) } \\
\hline
\end{tabular}

Source: own study.

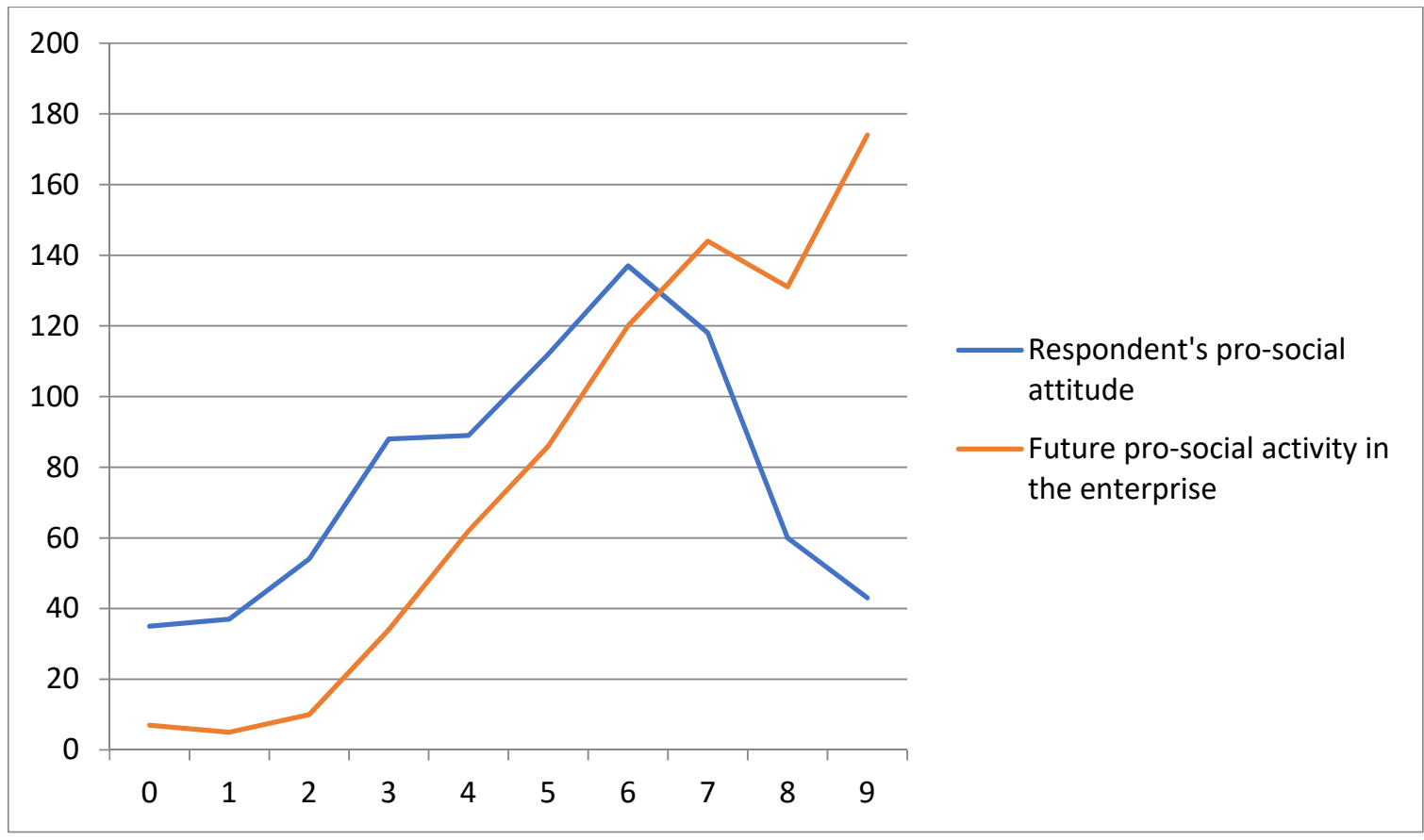

Figure 3. The structure of the pro-social orientation of the younger generation. Source: own study (based on Table 3).

As shown by the data in Table 3 and Figure 3, most young people (43.7\%) are moderately pro-social. Groups of low and high pro-social attitude consist of a similar number of respondents $(27.7 \%$ and $28.6 \%)$. There is a clear disproportion in the range of high pro-social orientation between the current pro-social activity of young people and their declarations regarding the inclusion of pro-social activities in company management. Twenty-eight and six tenths percent of the respondents belong to this range, while $58.1 \%$ of the respondents declare their future pro-social behavior. This means that some people with low and medium environmental friendliness declare high involvement in pro-social activities of enterprises. These declarations are not reflected in their current pro-ecological attitudes. Therefore, their future pro-ecological activities in companies can be doubted. Declarations of people who rank in the high range of pro-social attitudes are more credible because they reflect their current high pro-social activity.

As in the case of future pro-ecological activities, young people are not willing to spend a significant part of the profits of their future companies on financing pro-social projects. As shown in Table 3 and Figure 3, only 28.2\% of respondents want to allocate over $29 \%$ of their enterprises' profit to financing such projects. 
The results of the study indicate that the younger generation is not pro-ecological and pro-social enough. Only about $1 / 3$ of young people are highly pro-ecological and pro-social. This part of the younger generation gives a high guarantee of intensive inclusion of their enterprises in sustainable development. In other cases, declarations regarding high activity in this area are not fully credible because they come from people who are not highly pro-ecological or pro-social. Therefore, the majority of the younger generation is not prepared to implement and use sustainable management in energy companies. This field of management requires extensive knowledge and competences in the field of sustainability, necessary for planning, organizing, motivating, and controlling activities.

Implementation of sustainable management in enterprises is of great importance. It accelerates the transformation of non-sustainable energy sector into a fully sustainable one. It contributes to sustainable development and, in particular, to development of sustainable societies based on sustainable production and sustainable consumption. In the case of the energy sector, this pertains to sustainable production and sustainable consumption of electricity.

Preparing the younger generation to actively engage in sustainable management in energy companies requires much more intensive education at all levels of education. Only the combination of high pro-ecological and pro-social sensitivity with reliable knowledge about sustainable development will bring the desired effects in the form of young people's contribution to the balancing of intergenerational needs. It is especially recommended in higher education at universities educating in the field of management to create courses of study entitled Sustainable Management. In the case of universities with an energy profile, such studies should be entitled Sustainable Management in the Energy Sector. One has to remember that a sustainable manager, in order to efficiently implement ecological and social goals of an energy company, should have at their disposal human resources, which are sustainable members of his team. Therefore, it is not enough to educate only sustainable managers for the needs of sustainable management. Sustainable employees that do not perform managerial functions are also needed.

There are some limitations to the study conducted. The first concerns the evolution of attitudes and views of the younger generation regarding sustainable development. In the case of some young people, the degree of pro-ecological and pro-social awareness discovered by the study and the intentions regarding pro-ecological and pro-social activity in energy companies may change before they start working in these organizations. In our opinion, it will not be a mass phenomenon because people aged 19-24 are already physically and mentally formed - they have their own views on sustainable development which are difficult to change. The second limitation is related to their holding top management positions in energy companies. Only some of them will occupy such positions.

\section{Conclusions and Discussion}

The continuation of the efforts to promote sustainable development in the energy sector by the younger generation in the future is an especially important issue. Will young people who will soon take over the power in energy companies follow the path of sustainable development, initiating and implementing pro-ecological and pro-social projects in their companies? The answer to this question is important because our planet is deteriorating at an accelerated pace. Slowing down the actions for sustainable development in the future at the present high rate of energy production and consumption means pushing the limits of nature's tolerance and further deterioration of the condition of the Earth.

The study conducted by the authors of this paper shows that only $33.9 \%$ of young people are highly environmentally friendly. Almost half of young people $(49.9 \%)$ declare high readiness to include pro-ecological activities in the management of their enterprises. This does not guarantee that the younger generation, occupying the highest positions in energy companies in the future, will fully engage their companies in sustainable development. The problem is that we do not currently know which of them will occupy the highest positions. The worst situation in terms of sustainable development will be observed if 
the future top managers of energy companies come from the group of people with low pro-ecological attitudes (17.1\% of the surveyed population) and low orientation towards future pro-ecological activities ( $8.7 \%$ of the surveyed population).

It is also alarming that $83.0 \%$ of young people show low and medium interest in environmental problems. The lack of knowledge about environmental threats and the possibility of counteracting them will certainly make it difficult to make professional decisions and implement actions regarding sustainable development in the energy sector in the future. There is a need for broader and universal education of the younger generation in the field of sustainable development at all levels of education (primary, secondary, higher and higher education). It is also important to give these subjects a high rank in the curricula, and not to treat them as an insignificant addition to the mainstream education. The quality of teaching, including the manner and attractiveness of the content, plays an important role in teaching sustainable development. It should attract the attention of the younger generation and arouse interest in this area of knowledge.

The results of the research on the part of the profit that young people would like to spend on financing pro-ecological projects in their enterprises are not optimistic either. According to the survey, only $26.3 \%$ of young people want to spend over $29 \%$ of their companies' profit on financing this type of activities.

Apart from pro-ecological attitude, pro-social attitude is the second area of interest for sustainability. According to the study, only $28.6 \%$ of young people are in the high pro-social range. This group of people gives a high guarantee of including pro-social activity in the management of enterprises because there is a convergence between their pro-social attitudes and declarations. Future pro-social activity in companies is declared by much more people $(58.1 \%)$. However, in many cases, there is a discrepancy between pro-social attitudes and declarations. Will young people, currently representing a low and medium in their enterprises level of environmental performance, be highly involved in pro-social activities in the future? Analyzing the results of the research, the authors of the paper have doubts about that.

As in the case of future pro-ecological activities, young people are not willing to spend a significant part of the profits of their future companies on financing pro-social projects. Only $28.2 \%$ of the surveyed people want to spend over $29 \%$ of their companies' profit on financing such projects.

In conclusion, the study showed that only about $1 / 3$ of the younger generation is highly environmentally friendly and pro-social. This group of young people will include pro-ecological and pro-social activities in the management of energy companies. The remaining declarations about high activity in these areas are not fully credible because they come from people who are not highly ecological or pro-social. Thus, most young people are not prepared to take up challenges in the field of sustainable management in energy companies. This management requires considering sustainability in planning, organizing, leadership, and control. Each of these functions includes many different types of activities that contribute to sustainable development. In order to implement them properly, it is necessary not only to demonstrate pro-ecological and pro-social sensitivity, but also to have appropriate knowledge and skills in the field of sustainability. Although the results of the study are pessimistic, by intensifying education and training, as well as promoting sustainable development among young people, many of them can still be persuaded and encouraged to engage in intensive pro-ecological and pro-social activities now and in the future.

Future research on the topic raised in this article should focus on:

- sustainable management adjustments to the specificity of the energy sector,

- features and predispositions of the younger generation to act as sustainable top managers in energy companies,

- $\quad$ activities aimed at preparing better the younger generation to sustainable management in energy companies, 
- knowledge and experience of the younger generation in the field of sustainable development,

- the presence of sustainable development in the education programmes of the younger generation (primary, secondary, higher education), and

- $\quad$ promoting sustainable development among the younger generation outside formal education systems.

Summarizing the content of this article, it is important, both in science and in practice, to pay more attention to the future of sustainable development in the energy sector. The current generation has initiated sustainable development in the energy sector. It is up to the next generation to continue these efforts. It cannot be assumed uncritically that the next generation will be more or less interested in sustainability than the present generation. The results of the research presented in this article support this thesis. The study has shown that the younger generation is not prepared to take up the challenges of sustainability in energy companies. A particular challenge is the implementation and development of sustainable management in these companies. The study revealed in advance this unfavorable phenomenon. Thanks to this, it is possible to take corrective measures in advance, in the form of intensified education in the field of sustainable development and its promotion among young people. This will prevent the suspension of activities in the field of sustainability development in the energy sector in the future. This would have negative consequences for the Earth and its inhabitants.

Author Contributions: Conceptualization: A.P., B.P.; Methodology: B.P., K.B.-R.; Software: A.P.; Validation: A.P. and K.B.-R.; Formal analysis: A.P.; Investigation: A.P., B.P.; Resources: B.P.; Data curation: B.P.; Writing—original draft preparation: A.P., B.P., K.B.-R.; Visualization: A.P., Supervision: A.P.; Project administration: B.P., K.B.-R.; Funding acquisition: A.P., K.B.-R. All authors have read and agreed to the published version of the manuscript.

Funding: This research received no external funding.

Institutional Review Board Statement: Not applicable.

Informed Consent Statement: Not applicable.

Data Availability Statement: Not applicable.

Conflicts of Interest: The authors declare no conflict of interest.

\section{References}

1. Thiele, L.P. Sustainability; Polity Press: Cambridge, UK, 2016; pp. 200-201.

2. Fogel, D. Strategic Sustainability; Taylor \& Francis Group: New York, NY, USA, 2016; pp. 6-48.

3. Jeanrenaud, S.; Jeanrenaud, J.-P. Challenging: An overview of our one planet predicament. In Sustainable Business. A One Planet Approach; Jeanrenaud, J.P., Jeanrenaud, S., Gosling, J., Eds.; John Wiley and Sons Ltd.: London, UK, 2017; pp. 7-14.

4. WWF International. Living Planet Report 2016. Risk and Resilience in A New Era; WWF International: Geneva, Switzerland, 2016; pp. 13-14.

5. Jay, S. Strategic environmental assessment for energy production. Energy Policy 2010, 38, 3489-3497. [CrossRef]

6. Pimentel, D.; Herdendorf, M.; Eisenfeld, S.; Olander, L.; Carroquino, M.; Corson, C.; McDade, J.; Chung, Y.; Cannon, W.; Roberts, J.; et al. Achieving a secure energy future: Environmental and economic issues. Ecol. Econ. 1994, 9, 201-219. [CrossRef]

7. Pang, X.; Mortberg, U.; Brown, N. Energy models from a strategic environmental assessment perspective in an EU context-What is missing concerning renewables? Renew. Sustain. Energy Rev. 2014, 33, 353-362. [CrossRef]

8. Haugan, G. Sustainable Program Management; CRC Press, Taylor \& Francis Group: New York, NY, USA, $2014 ;$ pp. 9-55.

9. Cohen, S. Sustainability Management; Columbia University Press: New York, NY, USA, 2011; pp. 146-155.

10. Bendyk, E. Czas apokalipsy. Polityka, Wydanie Specjalne Zagrożenia dla Globu. Jak ich Uniknać? Czas Apokalipsy; 2013; pp. 6-9.

11. Holden, E.; Linnerud, K.; Banister, D.; Schwanitz, V.J.; Wierling, A. The Imperatives of Sustainable Development; Taylor and Francis Group: London, UK; New York, NY, USA, 2018; pp. 11-24.

12. Lenox, M.; Chatterji, A. Can Business Save the Earth? Innovating Our Way to Sustainability; Stanford University Press: Redwood City, CA, USA, 2018; pp. 4-10.

13. Carbo, J.A.; Dao, V.T.; Haase, S.J.; Hargrove, M.B.; Langella, I.M. Social Sustainability for Business; Taylor and Francis Group: New York, NY, USA; London, UK, 2018; pp. 9-60. 
14. Ariansen, P. Sustainability, morality and future generations. In Towards Sustainable Development: On the Goals of Development the Conditions of Sustainability; Lafferty, W.M., Langhelle, W.M., Eds.; McMillian: London, UK, 1999; pp. 84-95.

15. Martin, D.; Schouten, J. Sustainable Marketing; Pearson: London, UK, 2014; pp. 10-19.

16. Ottosson, M.; Parment, A. Sustainable Marketing; Studentlitteratur: Lund, Sweden, 2015; pp. 14-17.

17. Karol, A.; Mashood, C. Eco-awareness: Imbibing environmental values in consumers. In Green Consumerism. Perspectives, Sustainability and Behavior; Singh, R., Duhan, M.P., Eds.; Apple Academic Press, CRC Press Taylor and Francis Group: Boca Raton, FL, USA, 2019; pp. 266-300.

18. Longoni, A. Sustainable Operations Strategies; Politecnico di Milano; Springer: Berlin/Heidelberg, Germany, 2014.

19. Emery, B. Sustainable Marketing; Pearson: New York, NY, USA, 2012; pp. 11-23.

20. Varghese, G.; Viswanathan, L. Green Practices for Greener Living: The Road Ahead. In Green Consumerism. Perspectives, Sustainability and Behavior; Malyan, R.S., Duhan, P., Eds.; CRC Press, Taylor and Francis Group: Boca Raton, FL, USA, 2019; pp. 83-100.

21. Andrés, M.; Agudelo, L.; Johannsdottir, L.; Davidsdottir, B. Drivers that motivate energy companies to be responsible. A systematic literature review of Corporate Social Responsibility in the energy sector. J. Clean. Prod. 2020, 247, 1-58.

22. Thorhallsdottir, T.E. Strategic planning at the national level: Evaluating and ranking energy projects by environmental impact. Environ. Impact Assess. Rev. 2007, 27, 545-568. [CrossRef]

23. Zheng, S.; Wang, R.; Mak, T.M.W.; Hsu, S.-C.; Tsan, D.C.W. How energy service companies moderate the impact of industrialization and urbanization on carbon emissions in China? Sci. Total. Environ. 2021, 751, 1-9.

24. Yan, X.; Zhang, Y.; Pei, L.-L. The impact of risk-taking level on green technology innovation: Evidence from energy-intensive listed companies in China. J. Cleaner Prod. 2021, 281, 1-31. [CrossRef]

25. Van der Waal, J.; Thijssens, T. Corporate involvement in sustainable development goals: Exploring the territory. J. Clean. Prod. 2020, 252, 125319. [CrossRef]

26. Pabian, A. Zarządzanie w koncepcji sustainability-Ujęcie funkcjonalne. Przegląd Organizacji 2013, 10, 5-7. [CrossRef]

27. Bossink, B. Eco-Innovation and Sustainability Management; Taylor \& Francis Group: New York, NY, USA; London, UK, 2012; pp. $1-50$.

28. Epstein, M.J.; Rejc Buhovac, A. Making Sustainability Work; Greenleaf Publishing: London, UK, 2014; pp. 95-170.

29. Eccles, R.; Serafeim, G. Zrównoważona strategia jako przewaga konkurencyjna przedsiębiorstw. Przegląd Organizacji 2013, 4, 48-56.

30. Daft, R.L.; Benson, A. Management; Cengage Learning: Hampshire, UK, 2016; pp. 211-240.

31. Jones, G.; George, J. Essentials of Contemporary Management; McGraw-Hill/Irwin: New York, NY, USA, 2011 ; pp. 189-200.

32. Templar, R. The Rules of Management. A Definitive Code for Managerial Success; Pearson: New York, NY, USA, 2015; pp. 116-130.

33. Koprowska, J. Zdrowy pracownik, silna firma. Harv. Bus. Rev. Pol. 2019, 10, 136-138.

34. Witzel, M. Organizing. In Sustainable Business. A One Planet Approach; Jeanrenaud, S., Jeanrenaud, J.-P., Gosling, J., Eds.; John Wiley and Sons Ltd.: London, UK, 2017; pp. 210-243.

35. Ghillyer, A. Management. A Real-World Approach; McGraw-Hill: New York, NY, USA, 2009; pp. $276-333$.

36. Doh, J.P.; Luthans, F. International Management; McGraw-Hill: New York, NY, USA, 2018; pp. 398-420.

37. Brzozowska, A.; Pabian, A.; Pabian, B. Sustainability in Project Management. A Functional Approach; Taylor \& Francis Group: Boca Ratan, FL, USA; London, UK; New York, NY, USA, 2021; pp. 1-202.

38. Bilińska-Reformat, K.; Stefańska, M. Young Consumer's Behaviours on Retail Market and Their Impact on Activities of Retail Chains. Bus. Excell. 2016, 2, 123-137. 